\title{
Trajetórias Educacionais de Pessoas com Surdocegueira Adquirida ${ }^{1}$ EDUCATIONAL TRAJECTORIES OF PEOPLE WITH ACQUIRED DEAFBLINDNESS
}

\author{
Raffaela LUPETINA ${ }^{2}$ \\ Catia Crivelenti de Figueiredo WALTER ${ }^{3}$
}

\begin{abstract}
RESUMO: Este estudo é um desdobramento de uma pesquisa de Doutorado em Educaçấo sobre a história de vida de indivíduos com surdocegueira adquirida, conforme Lupetina (2019). O artigo tem como objetivo trazer a narrativa dos surdocegos referente à trajetória educacional vivenciada por eles. Participaram, desta pesquisa, sete surdocegos de diferentes estados brasileiros que narraram sobre as suas vidas a partir da própria percepção, trazendo o protagonismo dos surdocegos como lugar de fala. As formas de comunicação utilizadas pelos surdocegos durante as entrevistas foram: Língua Brasileira de Sinais (Libras) tátil, Libras em campo reduzido, fala ampliada, fala estando perto e Tadoma. Os resultados indicaram que, apesar de trajetórias diferentes, os relatos possuem pontos em comum, como a insistência na oralização e na leitura labial para os surdocegos que possuem resíduo visual, em vez do incentivo ao uso da Libras; a ausência de profissionais especializados e materiais adaptados; e serem os únicos surdocegos nos espaços escolares em que estudaram. O estudo conclui que o protagonismo do surdocego em pesquisas acadêmicas ainda é muito raro e que o processo de inclusão escolar tem muito a caminhar, pois são pessoas que necessitam ter voz e direitos como cidadãos.
\end{abstract}

PALAVRAS-CHAVE: Educação Especial. Surdocegueira. Processo educacional. História de vida. Formas de comunicação.

\begin{abstract}
This study is an unfolding of a Doctoral research in Education about the life history of individuals with acquired deafblindness, according to Lupetina (2019). The article aims to bring the narrative of the deafblind regarding the educational trajectory experienced by them. Seven deafblind people from different Brazilian states participated in this research, who narrated about their lives from their own perception, bringing the protagonism of the deafblind as a place of speech. The forms of communication used by the deafblind during the interviews were: Brazilian Sign Language tactile, Brazilian Sign Language in reduced field, extended speech, near speech and Tadoma. The results indicated that, despite different trajectories, the reports have points in common, such as: insistence on oralization and lip reading for deafblind people who have visual residue, instead of encouraging the use of Brazilian Sign Language; absence of specialized professionals and adapted materials, and being the only deafblind people in the school spaces where they studied. The study concludes that the role of the deafblind in academic research is still very rare and that the process of school inclusion has a long way to go, as they are people who need to have a voice and rights as citizens.
\end{abstract}

KEYWORDS: Special education. Deafblindness. Educational process. Life history. Forms of communication.

\section{INTRODUÇÁO}

A surdocegueira é uma deficiência única, que contempla duas perdas sensoriais simultâneas, a auditiva e a visual. Para ser considerado surdocego, o indivíduo não precisa apresentar a perda total dos sentidos da audição e da visão, pois tendo a perda parcial de ambos já é classificado como surdocego. A primeira definição que se tem sobre a surdocegueira, de acordo

\footnotetext{
${ }^{1}$ https://doi.org/10.1590/1980-54702021v27e0237

${ }^{2}$ Professora do Instituto Benjamin Constant (IBC). Pesquisadora de Pós-Doutorado pelo Programa de Pós-Graduação em Educação Contextos Contemporâneos e Demandas Populares da Universidade Federal Rural do Rio de Janeiro (UFRRJ). Doutora em Educação pela Universidade do Estado do Rio de Janeiro (UERJ). Rio de Janeiro/RJ/Brasil. E-mail: raffalupetina@gmail.com. ORCID: https://orcid.org/0000-0002-5816-2550

${ }^{3}$ Professora Associada do Departamento de Educação Inclusiva e Continuada e do Programa de Pós-Graduação em Educaçâo da Faculdade de Educação da Universidade do Estado do Rio de Janeiro (UERJ). Rio de Janeiro/RJ/Brasil. E-mail: catiawalter@ gmail.com. ORCID: https://orcid.org/0000-0002-7033-8301
} 
com Datona (1976), é do Departamento de Educação Especial Americano, do ano de 1969: "deficiência auditiva e visual, cuja combinação causa problemas tão graves de comunicação e outros problemas de desenvolvimento da educação, que não pode ser adequadamente acomodada nos programas de Educação Especial somente para criança surda ou para criança cega" (p. 172).

Essa definição do final da década de 1960 já nos suscita reflexôes sobre os possíveis desafios educacionais e comunicacionais vivenciados pelos surdocegos. Masini (2002) traz uma definição mais atual sobre surdocegueira:

Surdocegueira é uma combinação da perda de audição e visão. De fato, uma pessoa surdacega, às vezes é totalmente surda e cega, mas muito frequentemente ela/ele é surdo com alguma visão ou cego com alguma audição. Algumas pessoas surdacegas têm memória auditiva e visual. [...]. A educação desses indivíduos mostra claramente a necessidade de abordagens individualizadas que reflitam o fato de que cada estudante surdocego tem necessidades específicas muito individuais. (p. 119-122).

É importante sabermos o nível de resíduo auditivo ou visual para aproveitarmos esse resíduo a fim de estabelecer uma forma de comunicação. Se o surdocego já tiver uma forma de comunicação estabelecida, esta precisa e deve ser respeitada. Quanto aos graus de comprometimento residual, eles podem ser: surdez moderada associada à cegueira; surdez moderada associada à baixa visão; surdez severa associada à cegueira; surdez severa associada à baixa visão; surdez profunda associada à cegueira; e surdez profunda, cegueira e deficiência física (CaderNascimento, 2012). Essas combinaçóes de diferentes graus de perdas sensoriais mostram-nos que o indivíduo com surdocegueira apresenta uma complexidade e que seus resquícios auditivos e/ou visuais precisam ser levados em consideração, pois isso irá interferir significativamente no seu processo de aprendizagem e na sua forma de comunicação.

A surdocegueira pode ser congênita ou adquirida ${ }^{4}$. O surdocego congênito é aquele que nasce ou adquire a surdocegueira antes da aquisição de uma língua (Língua de Sinais ou língua oral: no caso do Brasil a Língua Brasileira de Sinais - Libras ou a Língua Portuguesa). Já as pessoas com surdocegueira adquirida consistem em crianças, jovens e adultos que adquiriram a surdocegueira após a aquisição de uma língua (oral ou gestual).

Os surdocegos podem ser pessoas nascidas com audição e visão - nasceram ouvintes e videntes e, posteriormente, tornaram-se surdocegos; pessoas com perda auditiva ou surdas congênitas com problemas visuais adquiridos - primeiro perderam parcialmente a audição ou nasceram surdas e depois começaram a ter comprometimento da visão (Cader-Nascimento \& Costa, 2010; Masini, 2002); pessoas com perda visual ou cegueira com problemas auditivos adquiridos - primeiro perderam a visão e depois a audição. Essas são as possibilidades de ordem das perdas sensoriais. É importante lembrarmos que a idade e o tempo das perdas sensoriais irão interferir na forma de comunicação utilizada pelo surdocego posteriormente.

\footnotetext{
${ }^{4}$ Em algumas referências sobre surdocegueira podem ser encontrados termos como "surdocego pré-linguístico", "surdocego pós-linguístico", "surdocego pré-simbólico" e "surdocego pós-simbólico". Atualmente, o Grupo Brasil e a Associação Brasileira de Surdocegos (Abrasc) afirmam como mais correto o uso dos termos "surdocego congênito" e "surdocego adquirido" (Grupo Brasil, 2012), os quais adotamos nesta pesquisa.
} 
Desta pesquisa, participaram somente pessoas com surdocegueira adquirida, as quais perderam parcialmente ou totalmente os sentidos da audição e da visão ao longo da vida. As causas da surdocegueira adquirida podem ser: acidente vascular cerebral, Diabetes Mellitus, Doença Refsum, Meningite, Síndrome de Barder-Biedl, Síndrome de Hallgreen, Síndrome de Flynn-Aird, Síndrome de Cockayne, doença de Alstrom e Síndrome de Usher (CaderNascimento \& Costa, 2010; Masini, 2002). Dentre elas, a causa principal é a Síndrome de Usher. De acordo com Lupetina (2017), a Deafblind International afirma que cerca de 400.000 mil pessoas no mundo são afetadas pela Síndrome de Usher (dados atualizados em 2016).

Conforme Cader-Nascimento e Costa (2010) e Grupo Brasil (2012), existem três tipos de Síndrome de Usher. O tipo 1 tem como características: a surdez neurossensorial severa ou profunda congênita e bilateral (nos dois ouvidos); a alteração ou a ausência da função vestibular, podendo gerar problemas de equilíbrio; o comprometimento inicial abrange a cegueira noturna durante a infância ou adolescência, podendo ser progressiva. O tipo 2 tem como características: a deficiência auditiva leve a moderada, bilateral, simétrica e não progressiva; a função vestibular normal, uma vez que não apresenta problemas de equilíbrio; no final da infância ou adolescência aparecem escotomas (pontos cegos) que levam à cegueira na idade adulta. $\mathrm{O}$ tipo 3 apresenta como características: nasce com boa audição ou com perda auditiva de leve a moderada que se acentua após dez anos ou mais; a cegueira noturna e a presença de escotomas desde a infância até a fase adulta, assim, a pessoa é considerada legalmente cega no início ou no meio da idade adulta.

Segundo Godoy (2011) e Watanabe (2012), os profissionais que atuam diretamente com os surdocegos são: instrutor mediador e guia-intérprete. O instrutor mediador é o profissional indicado para estar com os surdocegos congênitos ou com as pessoas com deficiência múltipla, pois, além de dominar as diversas formas de comunicação dos surdocegos, também possui conhecimento sobre formas alternativas de comunicação, visto que o surdocego congênito e a pessoa com deficiência múltipla podem apresentar comprometimentos cognitivos que influenciam na forma de contato com os demais. Já o guia-intérprete é o profissional adequado para atuar com as pessoas com surdocegueira adquirida.

Para Lupetina (2017), o guia-intérprete é um profissional essencial no dia a dia do surdocego adquirido, principalmente no que diz respeito à comunicação e à locomoção. Muitas pessoas desconhecem as formas de comunicação dos surdocegos e, por isso, a presença do guia-intérprete é fundamental para mediar a conversa entre o surdocego e outras pessoas. Em relação à locomoção, a presença e o auxílio do guia-intérprete são indispensáveis, pois ele irá passar para o surdocego as informaçóes referentes ao espaço, aos objetos visuais, aos caminhos, às pessoas e aos demais possíveis interlocutores.

Sobre as formas de comunicação dos surdocegos, apresentamos o Quadro 1 com o nome do sistema de comunicação, uma breve definição e uma imagem de cada uma. 


\section{Quadro 1}

Principais formas de comunicação dos surdocegos.

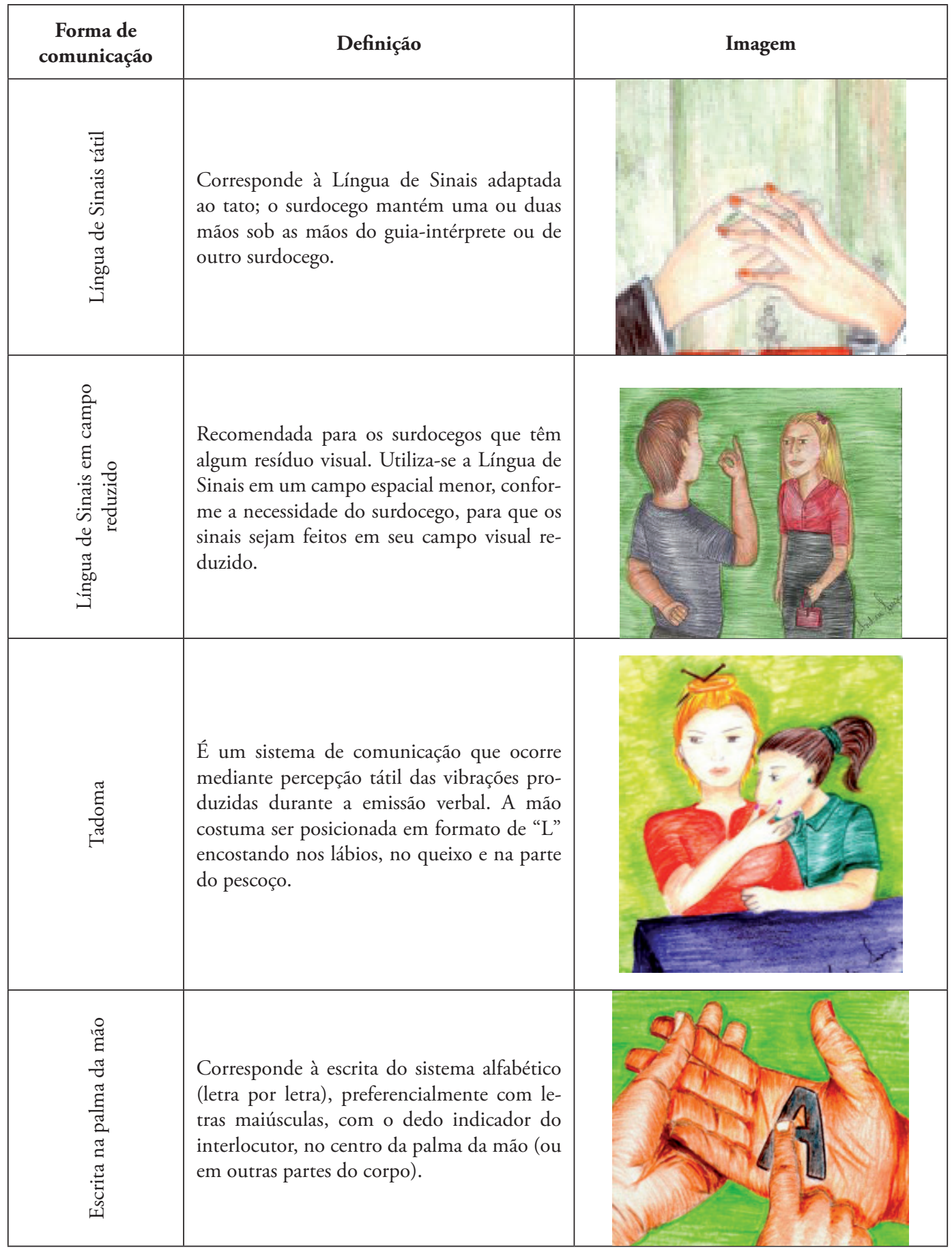




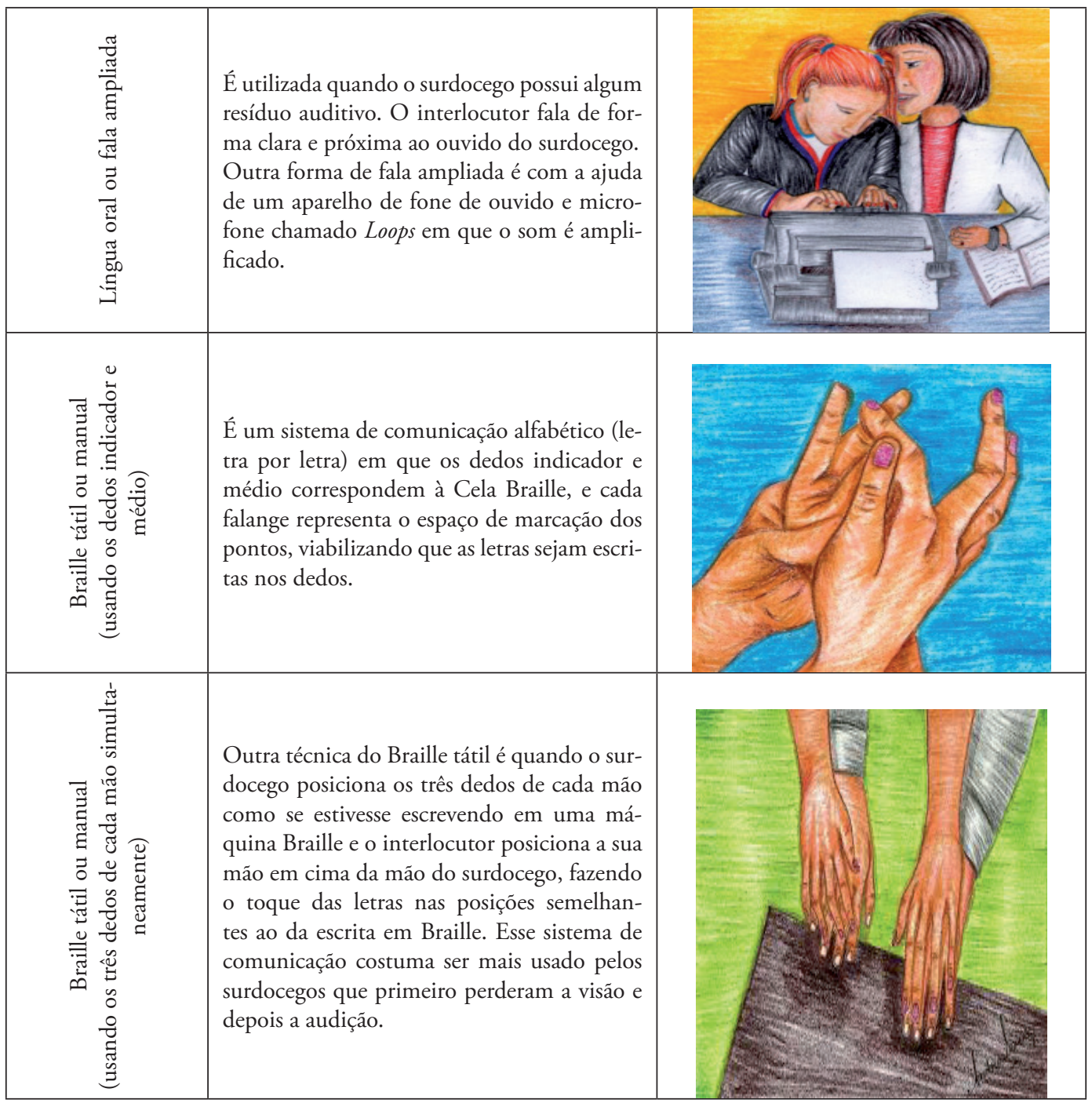

Nota. Imagens extraídas de Godoy (2011).

Consoante Lupetina (2019), a maioria das pesquisas não trazem os surdocegos como atores principais da pesquisa, privilegiando o depoimento de familiares dos surdocegos ou de profissionais que atuam na área. Dessa forma, sentimos a importância de trazer as percepçóes dos surdocegos contadas por eles próprios, na forma de comunicação utilizada por cada um deles.

Ainda são escassas, no Brasil, as pesquisas que se debruçam sobre a educação de surdocegos. A partir de um levantamento realizado no Catálogo de Teses e Dissertaçóes da Coordenação de Aperfeiçoamento de Pessoal de Nível Superior (Capes), em 8 de maio de 2021, ao digitar a palavra "surdocegueira" no campo de busca, encontramos 57 pesquisas sobre surdocegueira; entretanto, especificamente sobre "surdocegueira e educação", apenas 45 pesquisas foram encontradas. 
De acordo com Gomes (2016), os surdocegos possuem necessidades educacionais específicas e, muitas vezes, as pessoas desconhecem as particularidades da condição de uma pessoa surdocega. Segundo a autora: "O universo da surdocegueira é complexo e impóe muitos desafios aos gestores, professores e profissionais da educação para garantir o acesso e permanência desses indivíduos nas escolas a fim de que possam assumir seu papel na sociedade” (p. 32).

Das 45 pesquisas encontradas na varredura no Portal da Capes sobre "surdocegueira e educação", cabe destacarmos a dissertação de Watanabe (2017), a qual nos traz o Estado da Arte da produção científica sobre surdocegueira entre os anos de 1999 e 2015. O objetivo principal da autora foi contribuir para que outros pesquisadores tenham acesso às pesquisas realizadas no campo da surdocegueira, além de favorecer a disseminação de informaçóes para profissionais, familiares e voluntários que atuam na área. As 45 pesquisas encontradas no levantamento do Portal Capes, no entanto, náo descrevem claramente o processo educacional de pessoas com surdocegueira adquirida. Nesse sentido, trazemos aqui um questionamento principal que norteou este artigo: Como ocorreram os processos educacionais desses sujeitos?

Assim, partindo dos interesses e das narrativas próprias das pessoas com surdocegueira adquirida, este estudo busca descrever as impressóes, as lembranças e as reflexóes da trajetória educacional vivenciada por esse público-alvo, por meio do método de História de Vida. Desse modo, temos como objetivo trazer o depoimento de indivíduos com surdocegueira adquirida relacionado à trajetória educacional deles, a partir da metodologia escolhida, que tem como característica valorizar a narrativa dos participantes, promovendo o seu protagonismo.

\section{Método}

A metodologia adotada na realização das entrevistas foi a História de Vida, que traz o depoente como protagonista de sua própria história e o próprio condutor de sua narrativa. De acordo com Glat e Pletsch (2009), essa metodologia "considera como única fonte de dados, a estória ou relato de vida conforme narrada pelo sujeito durante a entrevista. O pesquisador não se preocupa em confirmar a 'veracidade' dos fatos, pois para ele o importante é o ponto de vista do sujeito" (p. 142). Na perspectiva de Silva et al. (2007):

Ao contar sua vida, o sujeito fala de seu contexto - fala do processo por ele experimentado, intimamente ligado à conjuntura social onde ele se encontra inserido. Ao se trabalhar o vivido subjetivo dos sujeitos, através do método de História de Vida, temos acesso à cultura, ao meio social, aos valores que ele elegeu e, ainda, à ideologia. (p. 32-33).

Nessa acepção, a metodologia de História de Vida valoriza a autopercepção do depoente, colocando o pesquisador em uma posição de expectador, o qual irá realizar o registro das narrativas dos atores principais da pesquisa. Além disso, essa metodologia tem como característica escutar e legitimar "vozes silenciadas" por meio da narrativa guiada por eles próprios. Para Glat e Antunes (2014), “a grande contribuição dessa abordagem metodológica é que permite que grupos historicamente silenciados e marginalizados conquistem um espaço para escuta de sua fala e, mais do que isso, reafirmem sua condição de protagonistas de suas próprias histórias” (p. 53).

No caso desta pesquisa, além de proporcionar visibilidade às vozes silenciadas, no sentido denotativo, essa metodologia também traz "sinais invisibilizados" e outras formas de 
comunicação que não costumam ser valorizadas. Esse é um diferencial deste estudo, pois pesquisas anteriores que utilizaram a História de Vida como metodologia têm como protagonistas pessoas oralizadas, que usam a fala como meio de comunicação. Ademais, esse estudo traz como depoentes surdocegos que utilizam outras formas de comunicação. Assim sendo, a participação do profissional guia-intérprete foi fundamental no processo de tradução, intepretação e transcrição da Língua de Sinais tátil para a Língua Portuguesa escrita.

Participaram da pesquisa sete pessoas com surdocegueira adquirida, sendo cinco do sexo feminino e dois do masculino, com idades variando entre 17 e 58 anos. O Quadro 2 a seguir indica o surdocego participante, a faixa etária, o estado de moradia, a forma de comunicação que utiliza e a situação sensorial atual. Optamos por colocar a situação atual dos resíduos sensoriais, pois quando se trata de pessoas com surdocegueira adquirida, o tempo de perda sensorial e a ordem das perdas (auditiva e visual) variam muito de pessoa para pessoa.

\section{Quadro 2}

Surdocegos que participaram da pesquisa.

\begin{tabular}{|c|c|c|c|c|c|}
\hline SC & Gênero & Idade & Moradia & Formas de comunicação & Situação sensorial atual \\
\hline $\begin{array}{c}\mathrm{SC} \\
1\end{array}$ & Feminino & 49 anos & RJ & $\begin{array}{c}\text { Libras tátil e Libras em campo } \\
\text { reduzido }\end{array}$ & Surda com pouco resíduo visual \\
\hline $\begin{array}{c}\mathrm{SC} \\
2\end{array}$ & Masculino & 39 anos & RJ & Libras tátil & Surdo com pouco resíduo visual \\
\hline $\begin{array}{c}\mathrm{SC} \\
3\end{array}$ & Feminino & 17 anos & RJ & Fala estando perto & $\begin{array}{c}\text { Resíduos visuais e auditivos } \\
\text { estáveis }\end{array}$ \\
\hline $\begin{array}{c}\mathrm{SC} \\
4\end{array}$ & Feminino & 53 anos & SP & Fala ampliada & $\begin{array}{c}\text { Cega com resíduo auditivo no } \\
\text { ouvido direito }\end{array}$ \\
\hline $\begin{array}{c}\mathrm{SC} \\
5\end{array}$ & Masculino & 58 anos & SP & Libras tátil e escrita no braço & Surdocego total \\
\hline $\begin{array}{c}\mathrm{SC} \\
6\end{array}$ & Feminino & 49 anos & SP & Tadoma & Cega com resíduo auditivo \\
\hline $\begin{array}{c}\mathrm{SC} \\
7\end{array}$ & Feminino & 48 anos & RS & $\begin{array}{l}\text { Fala ampliada e fala estando } \\
\text { perto }\end{array}$ & Resíduos visuais e auditivos \\
\hline
\end{tabular}

Nota. SC = surdocego; RJ = Rio de Janeiro; SP = São Paulo; RS = Rio Grande do Sul.

Os participantes surdocegos 1 e 2 utilizam a Libras tátil como forma de comunicação, pois primeiro perderam a audição e, portanto, começaram usando Libras (convencional, em campo aéreo) para se comunicar. Posteriormente, quando iniciou o processo de perda gradativa da visão, começaram a adaptar a Libras para a Libras tátil. A participante SC1 também utiliza a Libras em campo reduzido, porque ainda consegue enxergar alguns sinais com o resíduo visual que possui. Ela sabe, porém, que esse resquício da visão continuará diminuindo gradativamente e no futuro ela utilizará apenas a Libras tátil para se comunicar.

Todos os participantes da pesquisa são pessoas com surdocegueira adquirida. Durante a entrevista, alguns souberam informar a causa: a Síndrome de Usher. Alguns informaram até especificamente o tipo (1, 2 ou 3); outros não sabiam a causa, mas pelas características e pelo 
tempo das perdas, foi possível deduzirmos qual dos três tipos de Usher possuem. A participante SC1 não informou na entrevista a causa, mas, pelas informaçóes, possivelmente possui o tipo 1, uma vez que começou com a perda auditiva (que já chegou à perda total) e, atualmente, possui pouco resíduo visual, com perda gradativa. O participante SC2 informou que possui Síndrome de Usher com retinose pigmentar (tipo 1).

A participante SC3 possui resíduos auditivos e visuais bem significantes e estáveis, por isso consegue compreender a fala do interlocutor estando próxima dele. Por enquanto, ela ainda não precisa da fala ampliada (quando o interlocutor aproxima a boca do ouvido do surdocego), pois com o resíduo auditivo bilateral estável ela consegue compreender a fala do/a outro/a estando próxima. Possivelmente possui Síndrome de Usher tipo 2, a qual tem como característica a presença de resíduos auditivos e visuais estáveis na faixa etária em que ela se encontra.

A participante SC4 utiliza como forma de comunicação a fala ampliada, em que o interlocutor se aproxima do ouvido e fala mais alto. Como ela só possui resíduo auditivo no ouvido direito (e usa aparelho auditivo nesse ouvido) o interlocutor tem que ficar atento para sempre se aproximar do ouvido com audição remanescente. Ela nasceu com perda auditiva que foi gradativamente se acentuando, ficando surda do ouvido esquerdo e com resíduo auditivo no direito. Nasceu com retinose pigmentar e cegueira noturna, e aos 19 anos ficou cega. Durante a entrevista, ela informou que tem a Síndrome de Usher tipo 2.

O participante SC5 nasceu surdo e durante a infância e adolescência comunicava-se por Libras. Aos 24 anos, começou a perda visual no olho direito e aos 52 anos ficou cego, tornando-se surdocego total. Durante a entrevista, ele informou que tem a Síndrome de Usher tipo 1.

A SC6 nasceu ouvinte e vidente (termo utilizado para designar as pessoas que enxergam). Com seis anos, começou a utilizar aparelho auditivo e usa até hoje no ouvido que ainda possui resíduo auditivo. Aos nove anos, iniciou a perda visual e, aos 19 anos, ficou cega. Durante a entrevista, ela informou que tem a Síndrome de Usher tipo 3. Ela nasceu enxergando e escutando, estudou em escolas regulares, sempre falou e possui boa memória auditiva e visual e dos movimentos dos lábios. Quando começou a perda visual na infância, passou a tocar os lábios de sua mãe, iniciando um processo de leitura labial tátil, o que contribuiu, posteriormente, para a escolha do Tadoma como forma de comunicação.

A SC7 utiliza como forma de comunicação a fala ampliada e a fala estando perto. Em alguns momentos, ela consegue compreender o interlocutor estando bem próximo a ela e, em outros, ela precisa que o interlocutor aproxime a boca de seu ouvido e fale mais alto para que compreenda o que foi dito. Ela nasceu com perda auditiva e aos quatro anos começou a usar aparelho auditivo, e utiliza-o até hoje no ouvido em que ainda possui resíduo auditivo. Aos 27 anos, começou a ter dificuldades para enxergar, possui resíduo visual e utiliza óculos. Durante a entrevista, ela informou que tem a Síndrome de Usher e retinose pigmentar. As características das perdas indicam ser o tipo 2 .

\subsection{Procedimentos de RealizaÇáo e análise das entreVistas}

As entrevistas foram realizadas na localidade de moradia dos surdocegos. A primeira autora deste artigo foi até o encontro de cada surdocego para realizar a entrevista. Os três 
primeiros entrevistados moram no Rio de Janeiro, os três seguintes em São Paulo e a última participante no Rio Grande do Sul. As seis primeiras entrevistas foram filmadas e apenas a última entrevista foi gravada com gravador (a pedido da participante). Nesta pesquisa, três surdocegos não são oralizados; nesses casos, não havia a opção de utilizarmos apenas gravadores de áudio e a filmagem era condição sine qua non para a realização e legitimidade da pesquisa. Nas entrevistas em que os surdocegos eram oralizados, houve a presença do assistente de pesquisa, e nas entrevistas dos participantes não oralizados, houve a colaboração do guia-intérprete do respectivo estado de moradia do surdocego. As entrevistas começaram em 2017 e terminaram no início de 2019. As duraçóes variaram, sendo a entrevista mais curta com 22 minutos e a mais longa com 56 minutos.

As entrevistas realizadas em Língua de Sinais foram transcritas por dois guias-intérpretes separadamente e, posteriormente, foram comparadas. A primeira transcrição foi feita pelo guia-intérprete imparcial e a segunda transcrição pelo guia-intérprete que participou da entrevista. Por sua vez, as entrevistas com os participantes oralizados foram transcritas, inicialmente, pelo assistente de pesquisa e, posteriormente, pela pesquisadora (primeira autora), separadamente. Após a conferência das transcriçóes, ao existir alguma dúvida sobre uma palavra ou uma frase, optamos por omitir o texto indicado por reticências, para informar ao leitor que naquele trecho houve discrepância.

Nesse processo de transcrição, tivemos o cuidado de colocar o guia-intérprete que participou das entrevistas em Língua de Sinais como segundo transcritor e ter como primeiro transcritor o outro guia-intérprete, que não participou da entrevista, proporcionando uma garantia de maior fidelidade na transcrição dos dados. Nas entrevistas orais, o assistente de pesquisa atuou como primeiro transcritor e a primeira autora participou como segunda transcritora, com a finalidade de garantirmos mais distanciamento e, portanto, mais rigor na pesquisa.

Todos os participantes assinaram o Termo de Consentimento Livre e Esclarecido (TCLE) em que consta o propósito da pesquisa e informa que a participação do surdocego não era obrigatória, ou melhor, caso houvesse desistência não traria qualquer penalização ou necessidade de justificativa. Cabe salientarmos que não houve qualquer gasto financeiro do participante durante o estudo, assim como não houve pagamento por sua participação. Antes do início da pesquisa de campo, o projeto foi submetido na Plataforma Brasil e aprovado pelo Comitê de Ética em Pesquisa (CEP) da universidade onde a pesquisa foi realizada. O registro do número do Certificado de Apresentação para Apreciação Ética (CAEE) é 57970316.1.0000.5282 $\left(\text { Parecer } n^{\circ} 3.236 .619\right)^{5}$.

Em relação aos materiais e aos instrumentos, nas entrevistas realizadas no Rio de Janeiro, as filmagens foram feitas com a câmera de um celular iPhone, modelo 8 Plus, que ficou acoplado em um tripé para dar suporte e a filmagem ficar linear. O celular foi posicionado na horizontal para enquadrar no vídeo o entrevistado e o guia-intérprete em um mesmo plano, captando os movimentos das mãos, do corpo e as expressóes faciais, que são elementos fundamentais na comunicação dos surdocegos. Em São Paulo, o equipamento para filmagem

\footnotetext{
${ }^{5}$ Quando a investigação envolve seres humanos diretamente (com entrevistas ou coleta de células e/ou outros materiais humanos) ou indiretamente (pela observação de pessoas, prontuários ou materiais não acessíveis ao público), é importante e necessário que a pesquisa passe pelo Comitê de Ética em Pesquisa (CEP), para defender os interesses dos indivíduos e garantir a integridade e dignidade dos participantes, além de contribuir para o desenvolvimento da pesquisa.
} 
também foi a câmera de celular; a diferença foi que o assistente de pesquisa ofereceu o suporte, em vez de utilizarmos o tripé. No Rio Grande do Sul, a gravação de áudio foi realizada pelo aplicativo "gravador" existente no próprio iPhone. Após o procedimento de coleta, filmagens e gravação de voz, foram utilizados computador e papel. Os vídeos com as entrevistas foram vistos e revistos pelos transcritores para a realização das transcrições e, posteriormente, elas foram impressas, lidas e relidas para a elaboração das categorias. Uma delas foi sobre a trajetória educacional, a qual é foco do presente artigo, que enfatiza as questóes referentes ao processo educacional vivenciado pelos participantes surdocegos.

\section{Resultados E discussāo}

Nesta seção, traremos trechos das entrevistas que abordam a trajetória educacional dos surdocegos. Optamos por trazer essa temática pois foi um assunto naturalmente expresso por todos os surdocegos durante as entrevistas.

A primeira entrevistada frequenta uma instituição especializada na educação de deficientes visuais em que faz parte de atendimentos para o estudo de Braille e Língua de Sinais tátil. Sobre isso ela sinalizou: "eu amo estudar aqui. No futuro eu não vou ver mais, eu já conheço Libras tátil, aprendi aqui. Eu preciso dessa comunicação, eu não sei como será no futuro" (SC1, 49 anos, Libras tátil e Libras em campo reduzido). Além disso, ela frequenta aulas de artesanato, orientação e mobilidade na mesma instituição, para ter segurança e familiaridade no uso da bengala para se locomover.

Sobre a trajetória educacional anterior, SC1 sinalizou: "Antes estudei no INES [Instituto Nacional de Educação de Surdos]. Ingressei muito pequena, com seis anos. Eu vim para cá [Instituto Benjamin Constant] já velha. Não tenho mais o que falar. Tenho mais amigos aqui, aqui eu tenho a compreensão deles" (SC1, 49 anos, Libras tátil e Libras em campo reduzido).

O segundo entrevistado é o único participante que chegou na universidade. Atualmente, ele está na metade da Graduação em uma instituição especializada que tem alunos ouvintes e surdos (e agora um surdocego). Ele é o único surdocego na Graduação de toda a instituição. Sobre como estão sendo as aulas, ele sinalizou: "Fiquei feliz porque tive interação $e$ todos tiveram que se acostumar com a Libras tátil. No decorrer do curso eu encontrei dificuldades que demandaram um esforço coletivo, mas essa interação ao longo dos periodos, eu acredito, que será superada" (SC2, 39 anos, Libras tátil). Durante as aulas, ele tem guias-intérpretes que o auxiliam:

Eu tenho uma mesa, onde de um lado eu me sento e do outro lado o intérprete se senta. Na sala ficam três profissionais intérpretes. Os intérpretes fazem um revezamento entre eles, em média de 15 em 15 minutos. À medida que o professor leciona, eles repassam para mim através da Libras tátil o conteúdo que é ministrado, inclusive quando as aulas são lecionadas em Libras, eles transmitem para mim através da Libras tátil. Eles também me ajudam na compreensão dos textos através da Libras tátil com muita eficiência. (SC2, 39 anos, Libras tátil).

Ele também sinalizou que, durante a trajetória educacional na infância e na adolescência, houve uma grande insistência no uso da leitura labial e que sempre teve dificuldades com a oralização. Ademais, passou por reprovaçóes que o ajudaram a refletir que o sistema escolar não estava preparado para receber um aluno surdocego. 
A terceira entrevistada, que atualmente está terminando o Ensino Médio em uma escola pública regular, contou que, no segundo segmento do Ensino Fundamental, inicialmente não havia um/a ledor/a: "Do sexto até o oitavo ano eu não tinha ledora, eu tinha uma menina que ditava para mim, mas sempre ela reclamava que atrapalhava. Ai, no nono ano que essa ledora chegou. Ai, ela me acompanha até hoje na sala de aula e nas provas" (SC3, 17 anos, fala estando perto). Antes desse período ela não teve ledora e nem o auxílio de outra pessoa, passando por situaçóes vexatórias.

Na escola particular eu não tive ledora. E também näo tinha ninguém me ajudando. Eu me levantava, ia no quadro, ficava vendo. Equando eu me levantava e ficava no quadro para ler, ai [falavam]: "sai da frente, você não é transparente. Não sei o quê. Poste". Ficavam me zoando. (SC3, 17 anos, fala estando perto).

A quarta entrevistada, que, atualmente, só possui resíduo auditivo no ouvido direito, enxergou até os 19 anos e até essa idade conseguia fazer leitura labial: "Estudei em uma escola regular até o Ensino Médio. Eu tinha que sentar na primeira fileira porque o professor tinha que falar de frente pra que eu fizesse a leitura labial' (SC4, 53 anos, fala ampliada). Posteriormente, com o avanço da perda visual, ela não conseguia utilizar o resíduo visual de noite para voltar para casa, entáo contava com a ajuda dos colegas da escola. Todavia, esse auxílio permaneceu somente até a " 8 a série".

Tinha uns alunos que me ajudavam bastante, os colegas. Tinha, assim a noite, porque teve um periodo em que eu estudei das três da tarde às sete da noite. Eu näo conseguia ir para casa sozinha e minha mãe não tinha condiçôes de ir me buscar na escola, aí os amigos que me levavam até em casa, combinavam, pegavam também no outro dia, traziam e isso até a oitava série. Quando eu fui para o primeiro colegial eu já não contava com o apoio de ninguém, que os alunos amigos foram para outras escolas, né. (SC4, 53 anos, fala ampliada).

Além das dificuldades de seguir o trajeto da escola para casa, percebemos na narrativa da participante um ressentimento por alguns professores que não realizaram adaptaçóes pedagógicas para atender às necessidades educacionais específicas de uma aluna surdocega.

De alguns professores eu tive apoio e de outros não. Assim, eu não tive apoio do de Química e de Inglês, que é uma matéria bem complicada, principalmente pra quem tem surdocegueira, né? Ecom isso eu desanimava, porque até mesmo o professor de Quimica falava que eu fosse procurar uma Educação Especial que fosse me atender, isso lá em meados dos anos 80. Eu não conhecia nada, até tentei buscar informaçôes, mas infelizmente não consegui nada. Ai eu parei, eu parei de estudar no primeiro ano colegial. (SC4, 53 anos, fala ampliada).

Tanto na disciplina de Química quanto na de Inglês - como em qualquer disciplina - poderiam ser realizadas adaptaçóes para atender à aluna surdocega. Em Química, por exemplo, a adaptação principal que pode ser realizada é a transformação da tabela periódica convencional em uma tabela tátil, com as bordas e as divisóes em relevo e as letras ampliadas, em relevo e em Braille, para atender aos que possuem resíduo visual e aos que não enxergam. Os demais símbolos de química orgânica devem ser oferecidos em letra ampliada e Braille, com a presença do relevo nos desenhos das ligaçóes entre os símbolos. A parte de química inorgânica também pode ser adaptada com letra ampliada e em Braille. Essa sugestão de adaptação em 
Química é uma prática realizada no Instituto Benjamin Constant (IBC), com alunos cegos e surdocegos. Além dessas sugestóes, outras práticas de tabelas periódicas táteis são sugeridas por autores como Ferreira et al. (2016) e Maia (2012).

$\mathrm{Na}$ disciplina de Inglês, a parte de oralização precisa ser oferecida em Língua de Sinais e Língua de Sinais tátil, para os surdos e os surdocegos, respectivamente. No caso de SC4, que possui resíduo auditivo, a presença de um guia-intérprete em sala de aula garantiria a transmissão da mensagem por meio da fala ampliada. $\mathrm{O}$ conteúdo escrito pode ser adaptado para letra ampliada e Braille.

Durante o relato de SC5, verificamos que antes ele se considerava surdo com baixa visão, não se autodenominando surdocego. Ele nasceu surdo e a visão foi reduzindo progressivamente, começou a utilizar a Libras tátil com 32 anos, mas antes utilizava a Libras convencional, pois enxergava.

Era o único surdo com campo de visão reduzido. Quando tinha 33 anos, iniciei minha reabilitação [em uma instituição especializada], comecei uma vida nova. Me lembro da primeira vez como aluno surdocego. No processo de reabilitação, eu aprendi o Braille, a utilizar a máquina Perkins, passei a fazer leituras em Braille. Antes, estudei em uma escola particular [regular], ouvintes e surdos, tudo junto. Naquela época, eu enxergava com campo reduzido, não era cego. Na época do vestibular, eu participava de um curso com muitos ouvintes e eu o único surdo, o estudo era bom, estudava, mas na prova não conseguia, sentia dificuldades, não era totalmente ruim, era mais ou menos, foram duas tentativas e resolvi deixar de lado, e eu precisava trabalhar. (SC5, 58 anos, Libras tátil).

Quando ainda era surdo e enxergava, SC5 mencionou a insistência do sistema educacional na oralização em vez de valorizar a Língua de Sinais, tendo muita dificuldade em realizar leitura labial, pois preferia sinalizar. Essa dicotomia entre leitura labial e sinalização é uma discussão presente também em pesquisas sobre surdez. Toffolo et al. (2017) traz uma perspectiva interessante de que a leitura labial pode auxiliar no desempenho da leitura de surdos profundos usuários de Libras, o que também pode ocorrer com surdocegos. O principal é entendermos que cada surdocego irá trazer uma história de vida única e com tempos de perdas sensoriais variados e intensidades de resíduos sensoriais em diferentes níveis. Desse modo, para alguns surdocegos, a leitura labial será uma aliada no processo de comunicação; já, para outros, não será possível realizá-la, sendo mais confortável a sinalização. Também sobre leitura labial, a sexta participante, que estudou até o Ensino Fundamental, mencionou que os professores esqueciam que ela realizava leitura labial e que precisava olhar a boca deles.

Na época, os professores esqueciam que eu era uma criança surda e que eu fazia leitura labial. E eu pedia sempre para eles ficarem de frente para mim, mas eles esqueciam, viravam o rosto e eu: "Professor, professor!" virava. [...]. Me esforcei bastante para poder conseguir concluir o Ensino Fundamental, brigando com os professores para ficarem na frente comigo e mesmo assim os professores faziam aquela prova oral. (SC6, 49 anos, Tadoma).

A última entrevistada estudou em duas escolas especiais para surdos quando criança e depois estudou em duas escolas particulares. Ela contou que foi uma situação constrangedora que ocorreu durante o seu percurso educacional que a influenciou a se tornar uma judoca profissional, paralímpica e surdolímpica. Ela tinha vergonha de contar para a professora de Educação Física que não enxergava; por isso, não frequentava mais as aulas dessa disciplina e 
passou a não ter notas. Até que uma amiga contou para ela sobre a possibilidade de conquistar notas nessa disciplina por meio do judô e foi aí que começou a sua trajetória como judoca. O judô é uma modalidade corpo a corpo, sendo uma luta interessante para o surdocego, pois tem o tato como principal canal de interação. Nesse período, ela conheceu o treinador que a acompanha até os dias de hoje.

Quando eu tinha 14 anos, eu tinha que fazer Educação Física de tarde e daí a professora pediu para tirar os óculos para não bater a bola no rosto, ai depois eu náo sabia falar para ela. Eu fui embora. Ai depois de um mês, a minha mãe sempre buscava o boletim, aí ela mostrou e não tinha nada na nota de Educação Física, aí eu não sabia falar pra ela; e aí [...] eu acredito que a minha mãe entendeu, dai uma amiga minha fazia judô e ganhava nota na Educação Física, dai ela conversou com a minha mãe, então a minha mãe levou pra escola pra conversar com o treinador. Aí minha mãe conversou com o treinador, não me lembro o que ela falou muito bem, e aí comecei a fazer judô com o treinador para ganhar nota de Educação Física, tudo nove, dez, sempre, sempre, sempre e ai continuava e me formei em faixa preta e fiz curso de federação também. (SC7, 48 anos, fala ampliada e fala estando perto).

Os relatos dos surdocegos refletem as barreiras comunicacionais e sociais vivenciadas por eles, além da falta de um olhar atento e de conhecimento sobre as necessidades dos surdocegos. Os depoimentos ressaltam a falta de acessibilidade dentro e fora das instituiçóes escolares. Em contrapartida, temos trechos que demonstram um processo de autoaceitação e de histórias de superação.

Pesquisas como esta são fundamentais, uma vez que trazem visibilidade para essas questôes (mesmo que parcialmente, pois os artigos, em sua maioria, acabam repercutindo de forma limitada). Nessa perspectiva, entendemos que o emergir dessas histórias de vida traz ganhos sociais para os próprios surdocegos, para os familiares e para os profissionais que atuam com esses indivíduos táo únicos e plurais.

\section{Conclusótes}

A partir das histórias de vidas e das trajetórias educacionais dos indivíduos com surdocegueira adquirida, percebemos vários pontos em comum. Uma informação que todos os participantes salientaram foi que eram os únicos surdocegos nos espaços escolares em que estudaram, o que nos leva a pensar na grande quantidade de surdocegos que náo estão nos espaços escolares e/ou que evadiram das escolas. O depoimento de uma entrevistada que conta que seu professor disse que ela deveria estar em outra escola, que, por causa da perda gradativa da visão, não tinha como realizar o trajeto da escola para a casa sozinha, necessitando de auxílio de outras pessoas, e que depois não tinha ninguém que a ajudasse, demonstra que são diversos os motivos que podem levar o surdocego a evadir da escola.

Os surdocegos que, inicialmente, perderam a audição e, portanto, utilizavam a Língua de Sinais como forma de comunicação, ressaltaram que houve uma insistência na leitura labial e não os incentivavam a utilizar a Língua de Sinais. Enquanto os surdocegos que eram oralizados e conseguiam realizar a leitura labial comentaram que os professores viravam de costas ao escrever no quadro e continuavam a explicação de costas para o surdocego. Além 
disso, salientaram a ausência de ledores nas escolas e a falta de adaptação de material para o Braille e para a letra ampliada.

Outra questão importante trazida pelos surdocegos nas entrevistas é a ausência de intérpretes e de guias-intérpretes nas instituições escolares. As escolas não disponibilizam os profissionais adequados para garantir a acessibilidade do surdocego, o que também contribui para o desestímulo e a impermanência do surdocego nos bancos escolares. O guia-intérprete precisa ser mais reconhecido e valorizado. Durante esta pesquisa, a presença dos guias-intérpretes nas entrevistas dos surdocegos não oralizados e na tradução, intepretação e transcrição das entrevistas foi fundamental para garantirmos um rigor ao estudo.

Cabe ressaltarmos novamente a necessidade de respeitarmos e valorizarmos a forma de se comunicar de cada surdocego. A maioria das pesquisas sobre surdocegueira traz como participantes os familiares, os professores e/ou os profissionais que atuam com surdocegos, como fisioterapeutas e terapeutas ocupacionais, por exemplo. Desse modo, o protagonismo do surdocego nas pesquisas acadêmicas ainda é muito raro, e isso precisa ser mais bem explorado, pois são pessoas que necessitam ter voz e direitos como cidadãos.

Nesse sentido, a pesquisa realizada na Tese de Doutorado em Educação, assim como a produção deste artigo, traz um grande ineditismo, por se tratar de um estudo que privilegia os surdocegos como protagonistas, além de possibilitar que os surdocegos se expressem por meio da forma de comunicação de sua preferência, pois eles contaram sobre a sua trajetória educacional vivenciada de forma comandada pelo próprio surdocego.

\section{REFERÊNCIAS}

Cader-Nascimento, F. A. A. A., \& Costa, M. P. R. da. (2010). Descobrindo a surdocegueira: educação e comunicaçâo. EdUFSCar.

Cader-Nascimento, F. A. A. A. (2012). Surdocegueira e os desafios da educação inclusiva. In S. E. Orrú (Org.), Estudantes com necessidades especiais (v. 1, pp. 147-176). WAK.

Datona, R. (1976). Services for deaf-blind children. Exceptional Children, 43(3), 172-174. https://doi. org/10.1177/001440297604300320

Ferreira, J. E. V., Padilha, M. V. S., Oliveira, A. S., \& Ribeiro, P. E. S. (2016). Tabela periódica em braille para alunos deficientes visuais: construindo percepçóes táteis no ensino da química [Apresentação de artigo]. 56 Congresso Brasileira de Química, Belém, Pará, Brasil. http://www.abq.org.br/ cbq/2016/trabalhos/6/10082-23288.html

Glat, R., \& Antunes, K. C. V. (2014). A Metodologia de História de Vida na Pesquisa em Educação Especial: a Escuta dos Sujeitos. In L. R. Nunes (Org.), Novas trilhas no modo de fazer pesquisa em Educação Especial (1ª. ed., pp. 53-72). ABPEE.

Glat, R., \& Pletsch, M. D. (2009). O método de história de vida em pesquisas sobre autopercepção de pessoas com necessidades especiais. Revista Educação Especial, 22(34), 139-154. http://dx.doi. org/10.5902/1984686X

Godoy, S. A. (2011). Convivendo e aprendendo com o surdocego: o professor e os desafios da escola pública Paranaense. Produção didático-pedagógica. http://www.diaadiaeducacao.pr.gov.br/portals/ cadernospde/pdebusca/producoes_pde/2010/2010_uel_edespecial_pdp_shirley_alves_godoy.pdf 
Gomes, M. R. (2016). Surdocegueira: algumas considerações para a educação. Revista Fórum, 31, 25-38.

Grupo Brasil. (2012). Projeto Pontes e Travessias: Formação de Guia-Intérprete. Centro de Recursos nas áreas da Surdocegueira e Deficiência Múltipla Sensorial. Apostila elaborada por Dalva Rosa Watanabe e Shirley Rodrigues Maia. Programa da Ahimsa - Associação Educação para Múltipla Deficiência.

Lupetina, R. de M. (2017). The Formation of the Guide-interpreter to Work with Deafblind People. Journal of Studies in Education, 7(3), 146-162. https://doi.org/10.5296/jse.v7i3.11392

Lupetina, R. de M. (2019). Rompendo o silêncio: história de vida de individuos com surdocegueira adquirida [Tese de Doutorado não publicada]. Universidade do Estado do Rio de Janeiro, Rio de Janeiro, Brasil.

Maia, A. A. (2012). O ensino da tabela periódica para deficientes visuais [Monografia, Faculdade de Educação e Meio Ambiente, Faculdade de Licenciatura em Química, Faculdade de Educação e Meio Ambiente]. Repositório da FAEMA. http://repositorio.faema.edu.br/ bitstream/123456789/829/1/MAIA\%2C\%20A.\%20A.\%20-\%20O\%20ENSINO\%20DA\%20 TABELA\%20PERI\%C3\%93DICA\%20PARA\%20DEFICIENTES\%20VISUAIS.pdf

Masini, E. F. S. (2002). Do sentido... pelos sentidos... para o sentido. Vetor.

Silva, A. P., Barros, C. R., Nogueira, M. L. M., \& Barros, V. A. (2007). "Conte-me sua história”: reflexôes sobre o método de História de Vida. Mosaico: Estudos em Psicologia, 1(1), 25-35.

Toffolo, A. C. R. et al. (2017). Os benefícios da oralização e da leitura labial no desempenho de leitura de surdos profundos usuários da Libras. Revista Brasileira de Educação, 22, 1-24. https://doi. org/10.1590/S1413-24782017227165

Watanabe, D. R. (2012). Profissionais que atuam e apoiam a inclusão de pessoas com deficiência: Guiaintérprete, Instrutor Mediador, Tradutor Intérprete de Lingua de Sinais e Cuidador. Grupo Brasil de Apoio ao Surdocego e ao Múltiplo Deficiente Sensorial.

Watanabe, D. R. (2017). O estado da arte da produção científica na área da surdocegueira o Brasil de 1999 a 2015. [Dissertação de Mestrado, Universidade de São Paulo, Faculdade de Educação]. Repositório da Universidade de São Paulo. https://www.teses.usp.br/teses/disponiveis/48/48134/ tde-13062017-112304/pt-br.php

Recebido em: 29/10/2020

Reformulado em: 13/05/2021

Aprovado em: 25/05/2021 
LUPETINA, R. \& WALTER, C.C.F. 